\title{
RESEARCH NOTES
}

\section{CROSS-PROTECTION TESTS CONFIRM THE PRESENCE OF ETCH VIRUS ON TOB.ACCO IN PUERTO RICO ${ }^{1}$}

Tobacco-etch virus has recently been discovered in Puerto Rico. ${ }^{2}$ During the course of a survey ${ }^{3}$ conducted with the purpose of ascertaining the viruses present in our tobacco fields, symptoms resembling those of etch were noticed on tobacco plants inoculated in our laboratory with samples collected in the field. Further inoculations from some of these infected tobaccos reproduced the same symptoms, characterized both by chloritic mottling and patterns of white lines that appeared as etched on the surface of the affected leaves.

Preliminary inoculation on Chenopodium album L. ${ }^{4}$ and Physalis peruviana $\mathrm{L} .{ }^{5}$ both gave the characteristic necrotic primary lesions caused by etch virus on these hosts. Positive serological reactions were also obtained when extracts from the suspected etch-affected plants were mixed with an antiserum against severe etch virus prepared in our laboratory.

It has been shown by Holmes ${ }^{6}$ that in $P$. peruviana plants the conspicuous necrotic primary lesions and the subsequent systemic necrosis and defoliation of the severe etch strain did not occur as a result of inoculations made with the mild etch strain. The mild etch strain generally induces only a systemic chlorotic mottling disease in $P$. peruviana. Cross-protection tests in $P$. peruviana thus afford a convenient method for identifying the etch virus group. Experiments were therefore undertaken to determine whether the virus under study is etch or not. This note presents the results of the experiment.

Sample 475 , which has given severe etch symptoms when inoculated on $P$. peruviana, was selected for study. Young $P$. peruviana plants were dusted with carborundum and inoculated with a mild etch virus strain. In about 6 days the inoculated plants showed vein-clearing, followed by systemic mottling, wrinkling, and deformation of leaves. No chlorotic or necrotic spots were observed. About 2 weeks later, when the plants had

1 Thanks are expressed to F. O. Holmes, W. H. Greenleaf, and C. W. Anderson for supplying the $P$. peruriana, $C$. album, and the mild etch virus strain, respectively.

2 López Matos, L., Evidence for the presence of the tobacco-etch virus in Puerto Rico. To be published soon.

3 Adsuar, J. and Pérez, J. E., To be published soon.

4 Greenleaf, W. H., Effects of tobacco-ctch virus on pepper (Capsicum sp.), Phytopath. $43564-70,1953$.

- Holmes, F. O., Quantitative measurements of tobacco-etch virus, (Abst.), Phylopalh. 3112,1941 .

6 - Quantitative measurements of a strain tobacco-etch virus, Phylopalh. 32 $1058-67,1942$. 


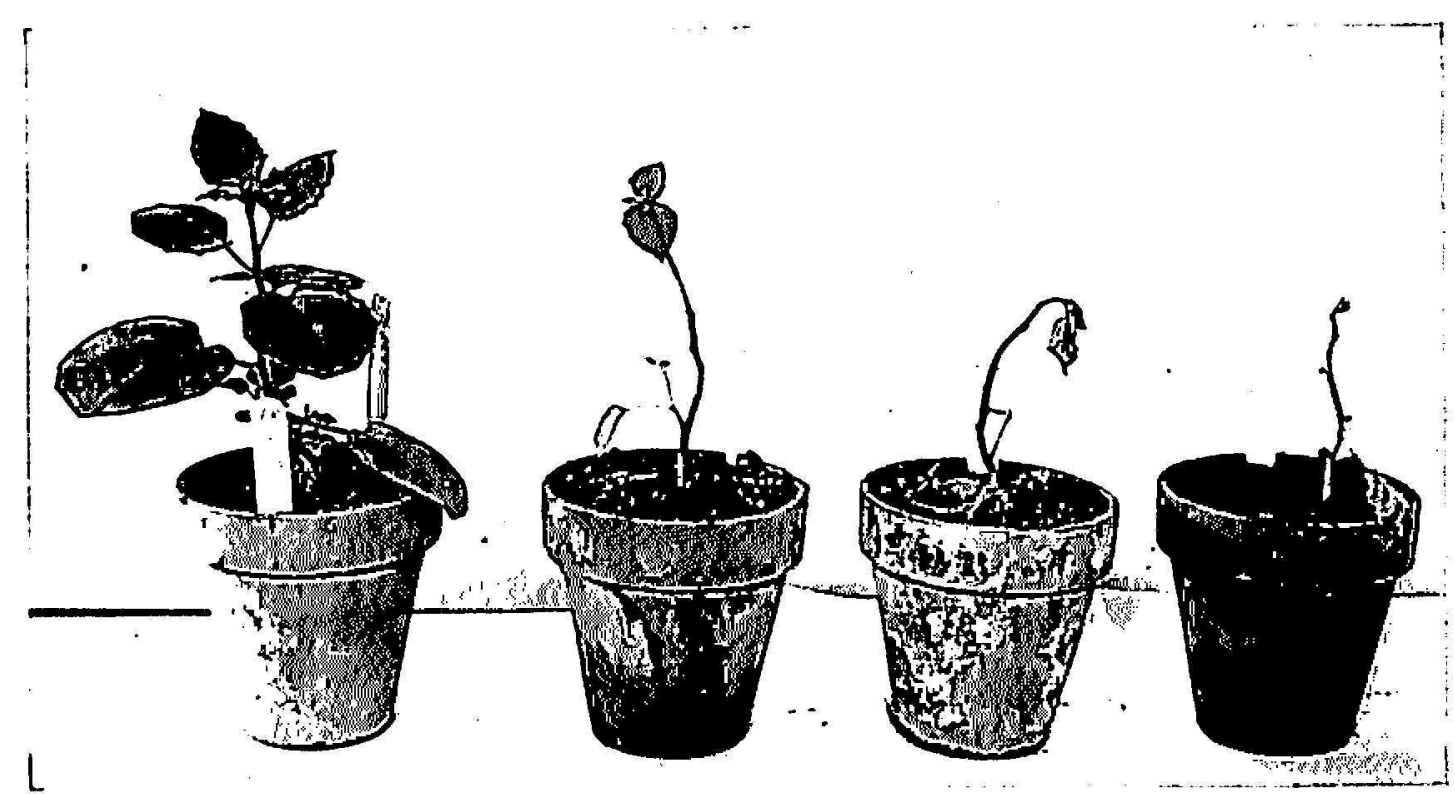

Fra. 1.-Protection against the severe etch virus in plants of Physalis peruviana. Plant on the extreme left inoculated first with the mild etch strain and subsequently with the severe etch (sample 475). The other plants inoculated with the severe etch only. Only the plant at the extreme left escaped systemic necrosis.

become thoroughly mottled, they were dusted again with carborundum powder and from 6 to 7 leaves on each plant were rubbed with severe etch virus (sample 475). At the same time an equal number of similar leaves of healthy $P$. peruviana plants were rubbed with the reinoculant to serve as checks.

In about 3 to 4 days the healthy $P$. peruviana plants inoculated with severe etch (sample 475) began to show vein-clearing of young uninoculated leaves. Almost simultaneously formation of chlorotic spots on inoculated leaves was observed followed by chlorotic spots, wrinkling, and deformation of leaves. A few days later the leaves that developed many lesions tended to become yellow and to absciss. Later on the plants developed a systemic necrosis and finally died. None of the $P$. peruviana previously inoculated with the mild etch strain and showing mottle presented the primary chlorotic spots nor the systemic necrosis caused by the severe etch virus. Figure 1 shows the specificity of protective inoculation with the mild etch virus.

In view of the above-presented cross-protection tests and the serological evidence mentioned before, we conclude that severe etch virus is present on tobacco in Puerto Rico.

The experiments were carried out in a wire-screen house during the months of March to June; the temperature inside the house fluctuated between $60^{\circ}$ and $100^{\circ} \mathrm{F}$.

José Adsuar

J.E. Pérez

Department of Plant Pathology 